\title{
High-pressure ethanol oxidation and its interaction with NO
}

Aragón Institute of Engineering Research (I3A). Department of Chemical and Environmental Engineering. University of Zaragoza. C/ Mariano Esquillor, s/n. 50018 Zaragoza. Spain

*uxue@unizar.es

\section{ABSTRACT}

Ethanol has become a promising biofuel, widely used as a renewable fuel and gasoline additive. Describing the oxidation kinetics of ethanol with high accuracy is required for the development of future efficient combustion devices with lower pollutant emissions. The oxidation process of ethanol, from reducing to oxidizing conditions, and its pressure dependence (20, 40 and 60 bar) has been analyzed in the $500-1100 \mathrm{~K}$ temperature range, in a tubular flow reactor under well controlled conditions. The effect of the presence of NO has been also investigated. The experimental results have been interpreted in terms of a detailed chemical kinetic mechanism with the GADM mechanism (Glarborg P, Alzueta MU, Dam-Johansen $K$ and Miller JA, 1998) as a base mechanism but updated, validated, extended by our research group with reactions added from the ethanol oxidation mechanism of Alzueta and Hernández (Alzueta MU and Hernández JM, 2002), and revised according to the present high-pressure conditions and the presence of NO. The final mechanism is able to reproduce the experimental trends observed on the reactants consumption and main products formation during the ethanol oxidation under the conditions studied in this work. The results show that the oxygen availability in the reactant mixture has an almost imperceptible effect on the temperature for the onset of ethanol consumption at a constant pressure, but this consumption is faster for the highest value of air excess ratio $(\lambda)$ analyzed. Moreover, as the pressure becomes higher, the oxidation of ethanol starts at lower temperatures. The presence of NO promotes ethanol oxidation, due to the increased relevance of the interactions of $\mathrm{CH}_{3}$ radicals and $\mathrm{NO}_{2}$ (from the conversion of $\mathrm{NO}$ to $\mathrm{NO}_{2}$ at high pressures and in presence of $\mathrm{O}_{2}$ ) and the increased concentration of $\mathrm{OH}$ radicals from the interaction of $\mathrm{NO}_{2}$ and water.

Keywords: ethanol; oxidation; high-pressure; nitrogen oxides; modeling. 
Minimizing particulate matter and nitrogen oxides $\left(\mathrm{NO}_{\mathrm{x}}\right)$ emissions from combustion, especially from transport, is a pressing need to improve the air quality, preserve the environment and comply with the increasingly restrictive laws. A prospective solution is fuel reformulation since its effects on emissions are immediate and can be implemented, without significant changes, in the design of the equipment. This reformulation implies the total or partial replacement of the conventional fuel by alternative ones, that may have been obtained in a more environmentally friendly way, for example, alcohols such as ethanol or butanol from biomass or wastes by biorefinery processes [1].

Ethanol $\left(\mathrm{C}_{2} \mathrm{H}_{5} \mathrm{OH}\right)$ is one of the most studied alcohols and its use, directly or as a gasoline additive, is spread worldwide. However, the cetane number, flash point and calorific value of ethanol are lower than those corresponding to diesel fuel, so it cannot be used directly in diesel engines. Therefore, ethanol must be blended with diesel fuel or biodiesel [2] and, working under the appropriate conditions, the emissions of CO, particulate matter and $\mathrm{NO}_{x}$ could be reduced [3].

The ethanol oxidation has been investigated in several works using laminar flames, shock tubes, flow reactors and rapid compression machines, as it has been summarized in the study of Mittal et al. [4]. More recently, Barraza-Botet et al. [5] carried out ignition and speciation studies in ethanol combustion in a rapid compression facility. For modeling predictions, they [5] used the detailed mechanism of Burke et al. [6,7] developed for $C_{1}-C_{3}$ hydrocarbons and oxygenated species oxidation, obtaining a good agreement with the experimental results.

47 However, despite its relevance for its applicability to internal combustion engines, the ethanol oxidation in 48 flow reactors under high-pressure conditions has not been previously studied. Therefore, reliable experimental data for validation of the kinetic models in this high-pressure regime become of high importance.

In this context, the aim of the present work is to extend the experimental database on ethanol oxidation with the study of its conversion under high-pressure conditions, in a flow reactor, for different air excess ratios, both in the absence and presence of nitric oxide (NO). NO may be formed in the combustion chamber 
interact with ethanol or its derivatives. The experimental results are analyzed in terms of a detailed chemical

kinetic mechanism to identify the main reaction routes occurring and to better understand the possible ethanol-NO interactions.

\section{Experimental methodology}

The ethanol oxidation experiments, both in the absence and presence of NO, have been carried out in a high-pressure flow reactor designed to approximate gas plug flow. The experimental set up is described in detail in Marrodán et al. [8] and only a brief description is provided here. A controlled evaporator mixer (CEM) has been used to feed an aqueous solution of ethanol ( $10 \%$ by weight) into the reaction system. The oxygen required to carry out each oxidation experiment depends on the air excess ratio analyzed $(\lambda$, defined as the inlet oxygen concentration divided by stoichiometric oxygen), and it has been supplied from gas cylinder through a Bronkhorst Hi-Tech mass flow controller. In the case of the experiments in the presence of NO, $500 \mathrm{ppm}$ of NO have been added to the feed gas flow. Table 1 lists the conditions of the different experiments.

The gas reactants are premixed before entering the reaction system, which consists of a tubular quartz reactor (inner diameter of $6 \mathrm{~mm}$ and $1500 \mathrm{~mm}$ in length) enclosed in a stainless-steel tube that acts as a pressure shell. The longitudinal temperature profile in the reactor was experimentally determined. An isothermal zone $( \pm 10 \mathrm{~K})$ of $56 \mathrm{~cm}$ was obtained in the reactor, which was considered as reaction zone. Nitrogen to balance up to obtain a total flow rate of $1 \mathrm{~L}(\mathrm{STP}) / \mathrm{min}$ has been used, resulting in a gas residence time dependent of the pressure and the temperature according to: $t_{r}(s)=261 \mathrm{P}(\mathrm{bar}) / \mathrm{T}(\mathrm{K})$.

The products were analyzed using an on-line 3000A Agilent micro-chromatograph equipped with TCD detectors and an URAS26 ABB continuous IR NO analyzer. The uncertainty of the measurements is estimated as $\pm 5 \%$, but not less than $10 \mathrm{ppm}$.

\section{Modeling}

80 Simulations of the experimental results obtained in the ethanol high-pressure oxidation, in the absence and 
[9]. The detailed mechanism used in this work has been built up by our research group from the GADM mechanism [10], progressively updated (e.g. $[11,12])$ and modified to consider the different experimental conditions, such as the high-pressure and/or the different compounds involved [13-17]. In the case of ethanol, the reaction subset proposed by Alzueta and Hernández [18] in an atmospheric ethanol oxidation study has been included in the mechanism compiled in this work. Formic acid $(\mathrm{HCOOH})$ has been identified as an intermediate in oxidation of dimethyl ether [19], which is an isomer of ethanol, so the reaction subset for formic acid oxidation proposed by Marshall and Glarborg [20] has also been included in the mechanism. The thermodynamic data for the species involved are taken from the same sources as the original mechanisms. The complete mechanism (137 species and 798 reactions) is provided as Supplementary Material in CHEMKIN format.

\section{Results and discussion}

A study of ethanol oxidation at high pressure (20, 40 and 60 bar), in the $500-1100 \mathrm{~K}$ temperature range, has been carried out, for different air excess ratios $(\lambda=0.7,1$ and 4$)$, both in the absence and in the presence of NO.

\subsection{Oxidation of ethanol in the absence of NO}

Figure 1 shows an example of the results for ethanol consumption and $\mathrm{CO}$ and $\mathrm{CO}_{2}$ formation as a function of temperature for the conditions of set 4 in Table 1, i.e., 20 bar, stoichiometric conditions $(\lambda=1)$ and in the absence of NO. From now on, experimental results are denoted by symbols, and modeling calculations by lines. In general, there is a good agreement between the experimental results and model predictions. Under these conditions, the ethanol conversion starts at approximately $725 \mathrm{~K}$, the same temperature as for the onset of $\mathrm{CO}$ formation whose concentration peaks at $775 \mathrm{~K}$. At the highest temperatures, ethanol and $\mathrm{CO}$ are completely oxidized to $\mathrm{CO}_{2}$.

Figure 2 shows the concentration of ethanol and of the main products quantified $\left(\mathrm{CO}, \mathrm{CO}_{2}, \mathrm{CH}_{3} \mathrm{CHO}_{2} \mathrm{C}_{2} \mathrm{H}_{4}\right.$, $\mathrm{CH}_{4}, \mathrm{CH}_{3} \mathrm{OH}, \mathrm{H}_{2}$ ), for different air excess ratios (from $\lambda=0.7$ to $\lambda=4$ ), at a constant pressure of 20 bar, and in the absence of NO. The oxygen availability in the reactant mixture does not modify significantly the 
temperature for the onset of ethanol conversion at a given pressure. In an ethanol oxidation study at atmospheric pressure, Alzueta and Hernández [18] observed that the ethanol oxidation occurs at lower temperatures for very oxidizing conditions $(\lambda=35)$, and small differences between $\lambda=0.7$ and $\lambda=1$ were found. The biggest discrepancies can be found in the experimental and modeling results for $\mathrm{CH}_{4}$, for reducing and stoichiometric conditions, and $\mathrm{CH}_{3} \mathrm{OH}$, minor products compared to $\mathrm{CO}$ and $\mathrm{CO}_{2}$. The same tendencies can be observed for the other pressures studied in this work, although these results are not shown. In order to further evaluate the influence of air excess ratio on ethanol oxidation, given the little influence found for $\lambda=1$ and $\lambda=4$, model calculations for $\lambda=35$, very fuel-lean conditions, have been carried out. The theoretical results obtained for $\lambda=35$ (Figure 2) are almost the same than those for $\lambda=4$, for ethanol, acetaldehyde $\left(\mathrm{CH}_{3} \mathrm{CHO}\right)$ and $\mathrm{CO}$ and $\mathrm{CO}_{2}$ concentrations, but lower amounts of $\mathrm{CH}_{4}, \mathrm{C}_{2} \mathrm{H}_{4}$ and $\mathrm{CH}_{3} \mathrm{OH}$ are predicted. So, it can also be deduced that for the high-pressure conditions studied in this work, there is almost no influence of the oxygen availability on the temperature for the onset of ethanol oxidation. Figure 3 shows the influence of the pressure change $(20,40$ and 60 bar) on the ethanol consumption and CO formation, which has been selected as one of the main products of ethanol oxidation. Independently of the stoichiometry analyzed, the consumption of ethanol starts at lower temperatures as the pressure is increased, approximately $100 \mathrm{~K}$ when moving from 20 to 60 bar. This behavior is also observed in the formation of $\mathrm{CO}$, which peaks at lower temperatures for the highest pressure analyzed. The oxidation of $\mathrm{CO}$ to $\mathrm{CO}_{2}$ is favored by an increase in pressure, as well as by an increase in the lambda value.

127 Considering the experimental procedure utilized in this work, a change in the pressure maintaining the total 128 gas flow rate, also implies a change in the gas residence time $\left(t_{r}(s)=261 P(b a r) / T(K)\right)$. Therefore, with the present mechanism, that describes well the experimental results, we have made different simulations to try to distinguish between the effect of gas residence time or pressure. This evaluation can be found as Supplementary Material, Figure S.1. The results indicate that both the pressure and the residence time have an appreciable effect on the ethanol conversion, which is shifted to lower temperatures when any of the above variables is increased. Accordingly, the results presented in Figure 3 correspond to the joint effect of pressure and residence time. 
In general, modeling predictions are in good agreement with the experimental observations. Consequently,

in this work, reaction rate analysis has been performed to identify the main ethanol consumption routes and products formation and the obtained results have been represented in a reaction pathway diagram in Figure 4 (left).

The ethanol consumption is initiated by its thermal dehydration to ethylene (reaction R.1), as this latter has been detected by gas chromatography, and also by its thermal decomposition through bond cleavage to $\mathrm{CH}_{2} \mathrm{OH}$ and $\mathrm{CH}_{3}$ radicals (reaction R.2). For example, for 20 bar and $\lambda=0.7$, at $725 \mathrm{~K}, 86 \%$ of the ethanol is being consumed through reaction R.2, and for $\lambda=4,95 \%$ of the ethanol consumption is produced through reaction R.1. This fact could explain the almost negligible effect of the oxygen availability on the temperature for the onset of ethanol consumption.

$\mathrm{C}_{2} \mathrm{H}_{5} \mathrm{OH}(+\mathrm{M}) \rightleftharpoons \mathrm{C}_{2} \mathrm{H}_{4}+\mathrm{H}_{2} \mathrm{O}(+\mathrm{M})$

$\mathrm{C}_{2} \mathrm{H}_{5} \mathrm{OH}(+\mathrm{M}) \rightleftharpoons \mathrm{CH}_{2} \mathrm{OH}+\mathrm{CH}_{3}(+\mathrm{M})$

147 In earlier studies involving ethanol oxidation in flow reactors [18,21], and in flames and jet stirred reactors 148 [22], the main reaction pathways for ethanol consumption were identified. The proposed reaction routes are

$\mathrm{C}_{2} \mathrm{H}_{5} \mathrm{OH}+\mathrm{R} \rightleftharpoons \mathrm{CH}_{3} \mathrm{CHOH} / \mathrm{CH}_{2} \mathrm{CH}_{2} \mathrm{OH} / \mathrm{CH}_{3} \mathrm{CH}_{2} \mathrm{O}+\mathrm{RH}$

Under the conditions of the present work, these reactions also take place, especially that one involving $\mathrm{HO}_{2}$ radicals, as it was previously observed in the oxidation of other oxygenated compounds, such as dimethoxymethane [23], under high-pressure conditions. The hydroxymethyl radical $\left(\mathrm{CH}_{2} \mathrm{OH}\right)$, formed in reaction R.2 from ethanol, reacts with molecular oxygen to produce formaldehyde and more $\mathrm{HO}_{2}$ radicals (reaction R.4), which interact with ethanol (reaction R.3) producing the $\mathrm{CH}_{3} \mathrm{CHOH}$ radical, the dominant radical under the present conditions.

$\mathrm{CH}_{2} \mathrm{OH}+\mathrm{O}_{2} \rightleftharpoons \mathrm{CH}_{2} \mathrm{O}+\mathrm{HO}_{2}$

159 An example of the evolution along the reactor of the main consumption reactions for ethanol can be observed in Figure 4 (right), for 20 bar, $\lambda=1$ and $725 \mathrm{~K}$. At the beginning of the reactor, the ethanol 

$\mathrm{HO}_{2}$ (reaction R.3) becomes more relevant with the distance.

The $\mathrm{CH}_{3} \mathrm{CHOH}$ radical reacts with molecular oxygen (reaction R.5) producing acetaldehyde, which has been quantified by gas chromatography. Acetaldehyde interacts with the radical pool producing the acetyl radical $\left(\mathrm{CH}_{3} \mathrm{CO}\right)$, which thermally decomposes to $\mathrm{CO}$ and $\mathrm{CH}_{3}$ radicals.

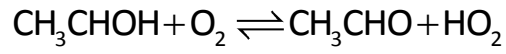

The reaction pathways involving the other two $\mathrm{C}_{2} \mathrm{H}_{5} \mathrm{O}$ radicals are of minor relevance compared to those already described, and very similar to those described in previous ethanol oxidation works (e.g. [22]). As it has been mentioned in the introduction, the mechanism of Burke et al. $[6,7]$ has been used in previous ethanol studies, e.g. [5]. Therefore, it has been considered interesting to compare the experimental results obtained in this work with those predicted with the present model and the Burke et al. model. This 172 comparison can be found as Supplementary Material, Figures S2-S10.

173 It can be observed that, in general, the model proposed in this work fits better the experimental results corresponding to the ethanol conversion onset temperature and the concentrations of ethanol, $\mathrm{CO}, \mathrm{CO}_{2}, \mathrm{H}_{2}$ and $\mathrm{C}_{2} \mathrm{H}_{4}$, while the Burke et al. model fits better the concentrations corresponding to $\mathrm{CH}_{4}$ and $\mathrm{CH}_{3} \mathrm{OH}$.

\subsection{Oxidation of ethanol in the presence of NO}

In the present work, the influence of the presence of NO in the reactant mixture on ethanol oxidation has also been analyzed. When burning any fuel in an air atmosphere at high temperatures, NO may be formed through the thermal NO formation mechanism by nitrogen fixation from the combustion air [24]. NO may be reduced by its interaction with ethanol and/or its derivatives, or may promote the ethanol oxidation in a mutually sensitized oxidation [25]. Therefore, the interaction between ethanol and NO has been considered 183 in the present work from both experimental and modeling points of view.

184 As it can be drawn from the discussion of the main reaction pathways for ethanol conversion in the absence of $\mathrm{NO}$, a high concentration of $\mathrm{CH}_{3}$ radicals is also expected in the presence of NO. Furthermore, under the present experimental conditions, it has been observed that, due to the high-pressure conditions and the presence of $\mathrm{O}_{2}, \mathrm{NO}$ added to the reactant mixture is converted to $\mathrm{NO}_{2}$ before entering the reactor. From the 
interaction between $\mathrm{CH}_{3}$ radicals and $\mathrm{NO}_{2}$ (reaction -R.6), the mechanism initially compiled in this work predicted an accumulation of nitromethane $\left(\mathrm{CH}_{3} \mathrm{NO}_{2}\right)$, whose formation was not detected experimentally. Another possible interaction between $\mathrm{CH}_{3}$ radicals and $\mathrm{NO}_{2}$ leading to $\mathrm{CH}_{3} \mathrm{ONO}$ may occur (reaction - $\mathrm{R}$.7).

$\mathrm{CH}_{3}+\mathrm{NO}_{2}(+\mathrm{M}) \rightleftharpoons \mathrm{CH}_{3} \mathrm{NO}_{2}(+\mathrm{M})$

$\mathrm{CH}_{3}+\mathrm{NO}_{2} \rightleftharpoons \mathrm{CH}_{3} \mathrm{ONO}$

193 In a high-pressure flow reactor study, Rasmussen and Glarborg [16] analyzed the effects of $\mathrm{NO}_{x}$ on $\mathrm{CH}_{4}$ oxidation, through ab initio calculations. Their calculations indicated that the formation of $\mathrm{CH}_{3} \mathrm{ONO}$ is energetically unfavorable, but, if formed, it would dissociate to $\mathrm{NO}$ and methoxy radical $\left(\mathrm{CH}_{3} \mathrm{O}\right)$.

Therefore, because of the high $\mathrm{CH}_{3}$ and $\mathrm{NO}_{2}$ concentrations expected and no $\mathrm{CH}_{3} \mathrm{NO}_{2}$ detection, the $\mathrm{CH}_{3} \mathrm{ONO}$ reaction to $\mathrm{CH}_{3}$ and $\mathrm{NO}_{2}$ (reaction R.7) has been included in our mechanism. There is not much information in bibliography regarding this reaction and its kinetic parameters. So, the value of $7.00 \times 10^{10} \mathrm{~cm}^{3} \mathrm{~mol}^{-1} \mathrm{~s}^{-1}$ proposed by Canosa et al. [26] has been adopted for reaction R.7. As it can be seen in Figure 5, in the concentration profiles of ethanol and $\mathrm{CO}$, the predictions of the model improved considerably after including reaction $\mathrm{R} .7$ in the mechanism.

Figure 6 (top) shows a comparison between the experimental results (symbols) and model predictions (lines) obtained during ethanol oxidation, in the presence of NO, for different air excess ratios and different pressures. Compared to Figure 3, the presence of NO promotes ethanol oxidation shifting the onset of ethanol oxidation to lower temperatures, a difference of 100-125 K approximately. As also occurred in the absence of NO, the available oxygen in the reactant mixture does not modify the temperature for the onset temperature. Figure 6 (bottom) shows the experimental and theoretical NO concentration results for different air excess ratios and 20 bar, and also other pressures for $\lambda=4$. Modeling predictions are shifted to higher temperatures, approximately $50 \mathrm{~K}$, compared to experimental results. At low temperatures, as previously mentioned, the $\mathrm{NO}$ fed to the system is converted to $\mathrm{NO}_{2}$ through reaction $\mathrm{R} .8$, and it is not thus 
214 pressure values influence the NO concentration, in the way that increasing the amount of oxygen in the reactant mixture or increasing the pressure, results in a lower amount of NO experimental or predicted.

$2162 \mathrm{NO}+\mathrm{O}_{2} \rightleftharpoons 2 \mathrm{NO}_{2}$

217 Once formed, $\mathrm{NO}_{2}$ reacts with $\mathrm{CH}_{3}$ radicals originated from ethanol to produce $\mathrm{CH}_{3} \mathrm{ONO}$ (reaction - $\mathrm{R} 7$ ), which 218 decomposes rapidly into $\mathrm{CH}_{3} \mathrm{O}+\mathrm{NO}$. As a consequence, $\mathrm{NO}$ is detected again, especially for 20 bar and $\lambda=0.7$, 219 because an increase in the value of pressure or lambda favors reaction R.8.

$220 \mathrm{NO}_{2}$ can also react with $\mathrm{H}_{2} \mathrm{O}$ to produce $\mathrm{HONO}$ and $\mathrm{OH}$ radicals (reaction R.9), which promote ethanol 221 conversion. The HONO formed decomposes to produce NO (reaction R.10).

$222 \mathrm{NO}_{2}+\mathrm{H}_{2} \mathrm{O} \rightleftharpoons \mathrm{HONO}+\mathrm{OH}$

$\mathrm{HONO}(+\mathrm{M}) \rightleftharpoons \mathrm{NO}+\mathrm{OH}(+\mathrm{M})$

224 The same reactions (R.9 and R.10), but in the reverse sense, were the cause of a slightly inhibiting effect of ethanol conversion by NO observed in the ethanol oxidation at atmospheric pressure [18], under certain conditions.

In the presence of NO, the ethanol consumption routes are the same as those already described in the absence of NO. However, in the presence of $\mathrm{NO}$, the reaction pathways involving the $\mathrm{CH}_{3} \mathrm{CH}_{2} \mathrm{O}$ radical respectively.

$\mathrm{CH}_{3} \mathrm{CH}_{2} \mathrm{O}+\mathrm{M} \rightleftharpoons \mathrm{CH}_{3}+\mathrm{CH}_{2} \mathrm{O}+\mathrm{M}$

234 First-order sensitivity analyses for ethanol and $\mathrm{CO}$ have been performed for different air excess ratios and 20 235 bar, in the absence of NO and in the presence of NO.

236 The obtained ethanol results are in agreement with the ethanol consumption pathways previously described 237 and can be found as Supplementary Material, Figure S11. In the absence of NO, the most sensitive reaction 238 is the hydrogen abstraction reaction by $\mathrm{HO}_{2}$ (reaction R.3), which is the main reaction pathway for ethanol 239 consumption. The reaction $\mathrm{H}_{2} \mathrm{O}_{2}(+\mathrm{M})=\mathrm{OH}+\mathrm{OH}(+\mathrm{M})$ is also very sensitive due to the generation of $\mathrm{OH}$ radicals 
240 which can promote the consumption of ethanol by $\mathrm{H}$ abstraction reactions. In the presence of $\mathrm{NO}$, the 241 formation of $\mathrm{CH}_{3} \mathrm{CH}_{2} \mathrm{O}$ radical from ethanol (reaction R.3, $\mathrm{C}_{2} \mathrm{H}_{5} \mathrm{OH}+\mathrm{OH}=\mathrm{CH}_{3} \mathrm{CH}_{2} \mathrm{O}+\mathrm{H}_{2} \mathrm{O}$ ) and its thermal 242 decomposition (reactions R.11 and R.12) present a high sensitivity coefficient, becoming the dominant 243 ethanol consumption under these conditions. The $\mathrm{CH}_{3}$ radicals generated in reaction $\mathrm{R} .12$ may interact with 244 ethanol promoting its consumption. The formation of $\mathrm{HONO}$ from the interaction of $\mathrm{CH}_{2} \mathrm{O}+\mathrm{NO}_{2}$ $245\left(\mathrm{CH}_{2} \mathrm{O}+\mathrm{NO}_{2}=\mathrm{HCO}+\mathrm{HONO}\right)$ and its subsequent decomposition (reaction R.10, $\left.\mathrm{HONO}(+\mathrm{M})=\mathrm{NO}+\mathrm{OH}(+\mathrm{M})\right)$ 246 producing $\mathrm{OH}$ radicals are sensitive in the presence of $\mathrm{NO}$, because of the $\mathrm{OH}$ radicals generated that 247 promote ethanol conversion.

248 Moreover, the first-order sensitivity analysis for CO (Figure 7) indicates that, in the absence of NO, the most sensitive reaction is the thermal dehydration of ethanol to ethylene (reaction R.1). The subsequent reaction of ethylene with $\mathrm{O}_{2}$ presents a high sensitivity for all the values of lambda analyzed. Hydrogen abstraction reactions from ethanol with different radicals are also sensitive. In the presence of NO, as in the case of the sensitivity results for ethanol, hydrogen abstraction reactions by $\mathrm{OH}$ radicals to produce $\mathrm{CH}_{3} \mathrm{CH}_{2} \mathrm{O}$ radical and its subsequent decomposition are highly sensitive. The interaction of $\mathrm{NO}_{2}$ with $\mathrm{CH}_{2} \mathrm{O}$ to produce $\mathrm{HONO}$ and HCO presents the highest sensitivity coefficient for all the lambdas analyzed.

\section{Conclusions}

257 The oxidation of ethanol has been analyzed from both experimental and modeling points of view. The 258 influence on the process of the available oxygen in the reactant mixture (different air excess ratios: $\lambda=0.7,1$ 259 and 4), the change of pressure (20, 40 and 60 bar) and the presence or absence of NO has been analyzed in a tubular flow reactor, in the 500-1100 K temperature range.

In general, there is a good agreement between experimental and modeling predictions. The results show that, for the conditions studied in this work, at a constant pressure, the temperature for the onset of ethanol oxidation is roughly independent of the amount of oxygen available in the reactant mixture, but the ethanol conversion starts at lower temperatures as the pressure is increased. A reaction rate analysis indicates that the ethanol consumption is mainly initiated by thermal dehydration or decomposition. 
When $\mathrm{NO}$ is fed to the high-pressure system, it converts to $\mathrm{NO}_{2}$ before entering in the reactor. In view of the high expected concentration of $\mathrm{NO}_{2}$ and $\mathrm{CH}_{3}$ radicals (from the ethanol conversion), the reaction $\mathrm{CH}_{3} \mathrm{ONO} \rightleftharpoons \mathrm{CH}_{3}+\mathrm{NO}_{2}$ has been included in our mechanism, with clear improvements of the model predictions. In the presence of NO, the ethanol conversion is promoted due to the increased concentration of $\mathrm{OH}$ in the radical pool from the interaction of $\mathrm{NO}_{2}$ and water. As observed in the absence of $\mathrm{NO}$, the stoichiometry does not have a clear influence on the ethanol oxidation regime, whereas an increase in the pressure shifts the temperature for the onset of ethanol consumption to lower temperatures.

\section{Acknowledgements}

The authors express their gratitude to Aragón Government and European Social Fund (GPT group), and to MINECO and FEDER (Project CTQ2015-65226) for financial support. Ms. Marrodán acknowledges Aragón Government for the predoctoral grant awarded.

References

[1] Sarathy SM, Oßwald P, Hansen N, Kohse-Höinghaus K. Alcohol combustion chemistry. Prog. Energy Combust. Sci. 2014;44:40-102.

[2] Alviso D, Krauch F, Román R, Maldonado H, dos Santos RG, Rolón JC, Darabiha N. Development of a diesel-biodiesel-ethanol combined chemical scheme and analysis of reactions pathways. Fuel 2017; 191:411-426.

[3] An H, Yang WM, Li J. Effects of ethanol addition on biodiesel combustion: a modeling study. Appl. Energy 2015;143:176-188.

[4] Mittal G, Burke SM, Davies VA, Parajuli B, Metcalfe WK, Curran HJ. Autoignition of ethanol in a rapid compression machine. Combust. Flame 2014;161:1164-1171.

[5] Barraza-Botet CL, Wagnon SW, Wooldridge MS. Combustion chemistry of ethanol: ignition and speciation studies in a rapid compression facility. J. Phys. Chem. A 2016;120:7408-7418. 
[6] Burke SM, Metcalfe W, Herbinet O, Batton-Leclerc F, Haas FM, Santner J, Dryer FL, Curran HJ. An experimental and modeling study of propene oxidation. Part 1: speciation measurements in jetstirred and flow reactors. Combust. Flame 2014;161:2765-2784.

[7] Burke SM, Burke U, Mc Donagh R, Mathieu O, Osorio I, Keesee C, Morones A, Petersen EL, Wang W, DeVerter TA, et al. An experimental and modeling study of propene oxidation. Part 2: ignition delay time and flame speed measurements. Combust. Flame 2015;162:296-314.

[8] Marrodán L, Millera Á, Bilbao R, Alzueta MU. High-pressure study of methyl formate oxidation and its interaction with NO. Energy Fuels 2014;28:6107-6115.

[9] ANSYS Chemkin-Pro 17.2, Release 15151; Reaction Design: San Diego, 2016.

[10] Glarborg P, Alzueta MU, Dam-Johansen K, Miller JA. Kinetic modeling of hydrocarbon/nitric oxide interactions in a flow reactor. Combust. Flame 1998;115:1-27.

[11] Glarborg P, Alzueta MU, Kærgaard K, Dam-Johansen K. Oxidation of formaldehyde and its interaction with nitric oxide in a flow reactor. Combust. Flame 2003;132:629-638.

[12] Glarborg P, Østberg M, Alzueta MU, Dam-Johansen K, Miller JA. The recombination of hydrogen atoms with nitric oxide at high temperatures. Proc. Combust. Inst. 1999;27:219-227.

[13] Rasmussen CL, Hansen J, Marshall P, Glarborg P. Experimental measurements and kinetic modeling of $\mathrm{CO} / \mathrm{H}_{2} / \mathrm{O}_{2} / \mathrm{NO}_{x}$ conversion at high-pressure. Int. J. Chem. Kin. 2008;40:454-480.

[14] Rasmussen CL, Glarborg P. Measurements and kinetic modeling of $\mathrm{CH}_{4} / \mathrm{O}_{2}$ and $\mathrm{CH}_{4} / \mathrm{C}_{2} \mathrm{H}_{6} / \mathrm{O}_{2}$ conversion at high pressure. Int. J. Chem. Kin. 2008;40:778-807.

[15] Rasmussen CL, Andersen KH, Dam-Johansen K, Glarborg P. Methanol oxidation in a flow reactor: implications for the branching ratio of $\mathrm{CH}_{3} \mathrm{OH}+\mathrm{OH}$ reaction. Int. J. Chem. Kin. 2008;40:423-441.

[16] Rasmussen $\mathrm{CL}$, Glarborg P. Sensitizing effects of $\mathrm{NO}_{x}$ on $\mathrm{CH}_{4}$ oxidation at high pressure. Combust. Flame 2008;154:529-545.

[17] Giménez-López J, Rasmussen CT, Hashemi H, Alzueta MU, Gao Y, Marshall P, Goldsmith CF, Glarborg P. Experimental and kinetic modeling study of $\mathrm{C}_{2} \mathrm{H}_{2}$ oxidation at high pressure. Int. J. Chem. Kin. 2016;48:724-738. 
[18] Alzueta MU, Hernández JM. Ethanol oxidation and its interaction with nitric oxide. Energy Fuels 2002;16:166-171.

[19] Fischer SL, Dryer FL, Curran HJ. The reaction kinetics of dimethyl ether. I: High-temperature pyrolysis and oxidation in flow reactors. Int. J. Chem. Kinet. 2000;32:713-740.

[20] Marshall P, Glarborg P. Ab initio and kinetic modeling studies of formic acid oxidation. Proc. Combust. Inst. 2015;35:153-160.

[21] Abián M, Esarte C, Millera Á, Bilbao R, Alzueta MU. Oxidation of acetylene-ethanol mixtures and their

[22] Leplat N, Dagaut P, Togbé C, Vandooren J. Numerical and experimental study of ethanol combustion and oxidation in laminar premixed flames and jet-stirred reactor. Combust. Flame 2011;158:705-725.

[23] Marrodán L, Royo E, Millera Á, Bilbao R, Alzueta MU. High-pressure oxidation of dimethoxymethane. Energy Fuels 2015;29:3507-3517.

[24] Abián $\mathrm{M}$, Alzueta $\mathrm{MU}$, Glarborg P. Formation of $\mathrm{NO}$ from $\mathrm{N}_{2} / \mathrm{O}_{2}$ mixtures in a flow reactor: toward and accurate prediction of thermal NO. Int. J. Chem. Kinet. 2015;47:518-532.

[25] Taylor PH, Cheng L, Dellinger B. The influence of nitric oxide on the oxidation of methanol and ethanol. Combust. Flame 1998;115:561-567.

[26] Canosa C, Penzhorn RD, Sonntag C. Product quantum yields from the photolysis of $\mathrm{NO}_{2}$ at $366 \mathrm{~nm}$ in presence of ethylene. The role of $\mathrm{NO}_{3}{ }_{3}$. Ber. Bunsenges Phys. Chem. 1979;83:217-225. 
336 Table captions

337 Table 1. Matrix of experimental conditions. 
Table 1. Matrix of experimental conditions.

\begin{tabular}{cccccc}
\hline Set & Ethanol $(\mathrm{ppm})$ & $\mathrm{O}_{2}(\mathrm{ppm})$ & $\mathrm{NO}(\mathrm{ppm})$ & $\lambda$ & $\mathrm{P}(\mathrm{bar})$ \\
\hline 1 & 5000 & 10500 & 0 & 0.7 & 20 \\
2 & 5000 & 10500 & 0 & 0.7 & 40 \\
3 & 5000 & 10500 & 0 & 0.7 & 60 \\
4 & 5000 & 15000 & 0 & 1 & 20 \\
5 & 5000 & 15000 & 0 & 1 & 40 \\
6 & 5000 & 15000 & 0 & 1 & 60 \\
7 & 5000 & 60000 & 0 & 4 & 20 \\
8 & 5000 & 60000 & 0 & 4 & 40 \\
9 & 5000 & 60000 & 0 & 4 & 60 \\
10 & 5000 & 10500 & 500 & 0.7 & 20 \\
11 & 5000 & 10500 & 500 & 0.7 & 40 \\
12 & 5000 & 10500 & 500 & 0.7 & 60 \\
13 & 5000 & 15000 & 500 & 1 & 20 \\
14 & 5000 & 15000 & 500 & 1 & 40 \\
15 & 5000 & 15000 & 500 & 1 & 60 \\
16 & 5000 & 60000 & 500 & 4 & 20 \\
17 & 5000 & 60000 & 500 & 4 & 40 \\
18 & 5000 & 60000 & 500 & 4 & 60 \\
\hline & & & & &
\end{tabular}


341 Figure 1. Concentration of ethanol, $\mathrm{CO}$ and $\mathrm{CO}_{2}$ as a function of temperature, for the conditions named as 342 set 4 in Table $1(\lambda=1,20$ bar $)$.

Figure. 2. Influence of the air excess ratio on the concentration profiles of ethanol and main products (CO, $\mathrm{CO}_{2}, \mathrm{CH}_{3} \mathrm{CHO}, \mathrm{C}_{2} \mathrm{H}_{4}, \mathrm{CH}_{4}, \mathrm{CH}_{3} \mathrm{OH}, \mathrm{H}_{2}$ ) during ethanol oxidation, as a function of temperature, for the conditions named as sets 1,4 and 7 in Table 1 (20 bar).

Figure. 3. Influence of the pressure change on the concentration profiles of ethanol and $\mathrm{CO}$, as a function of temperature, for the conditions named as sets 1-9 in Table 1.

Figure 4. Left: reaction path diagram for ethanol consumption and product formation. Right: normalized rate-of-consumption coefficients for ethanol along the reactor (for the conditions of set 4 in Table 1: 20 bar, $353 \lambda=1$ and $725 \mathrm{~K})$.

Figure 5. Improvement in modeling predictions for ethanol and $\mathrm{CO}$ concentration, with and without reaction

Figure 6. Influence of the air excess ratio and pressure on the concentration profiles of ethanol (top) and NO (bottom) for the conditions named as sets 10, 13 and 16-18 in Table 1.

Figure 7. Sensitivity analysis for CO for different air excess ratios and 20 bar. Top: in the absence of NO (at $698 \mathrm{~K})$. Bottom: in the presence of NO (at $648 \mathrm{~K}) .\left({ }^{*}\right)$ The sensitivity coefficients have been divided by two. 


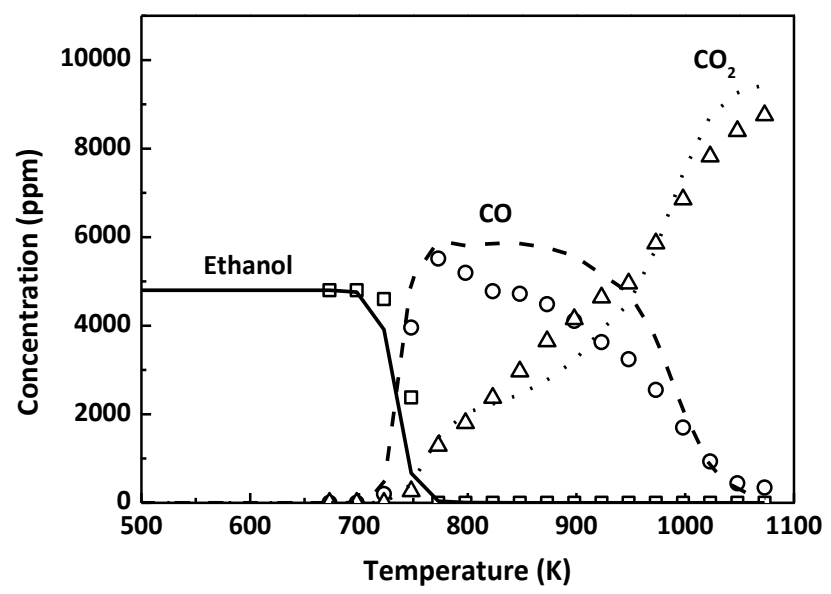

Figure 1. Concentration of ethanol, $\mathrm{CO}$ and $\mathrm{CO}_{2}$ as a function of temperature, for the conditions named as set 4 in Table $1(\lambda=1,20$ bar $)$. 

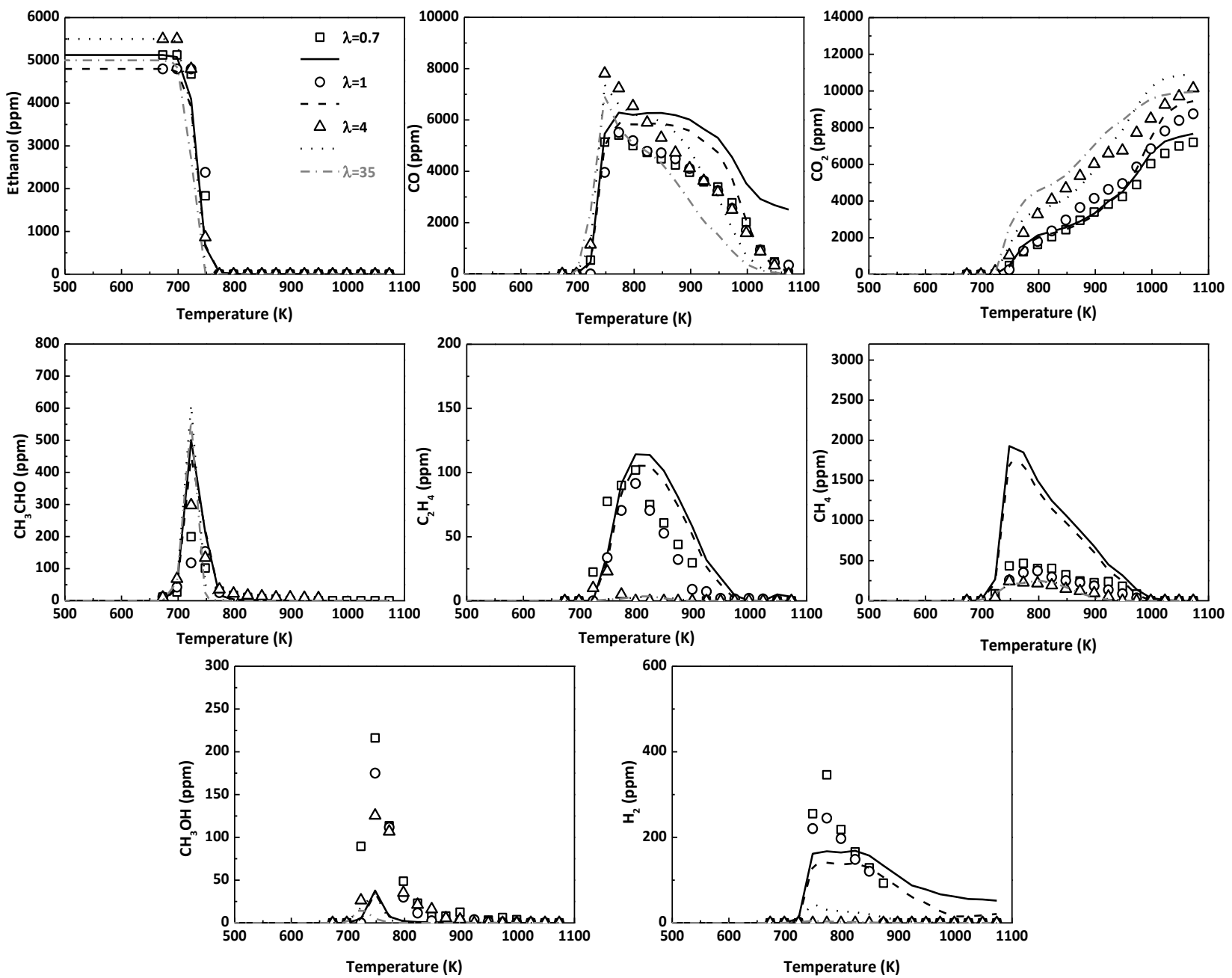

Figure. 2. Influence of the air excess ratio on the concentration profiles of ethanol and main products (CO, $\mathrm{CO}_{2}, \mathrm{CH}_{3} \mathrm{CHO}, \mathrm{C}_{2} \mathrm{H}_{4}, \mathrm{CH}_{4}, \mathrm{CH}_{3} \mathrm{OH}, \mathrm{H}_{2}$ ) during ethanol oxidation, as a function of temperature, for the conditions named as sets 1, 4 and 7 in Table 1 (20 bar). 


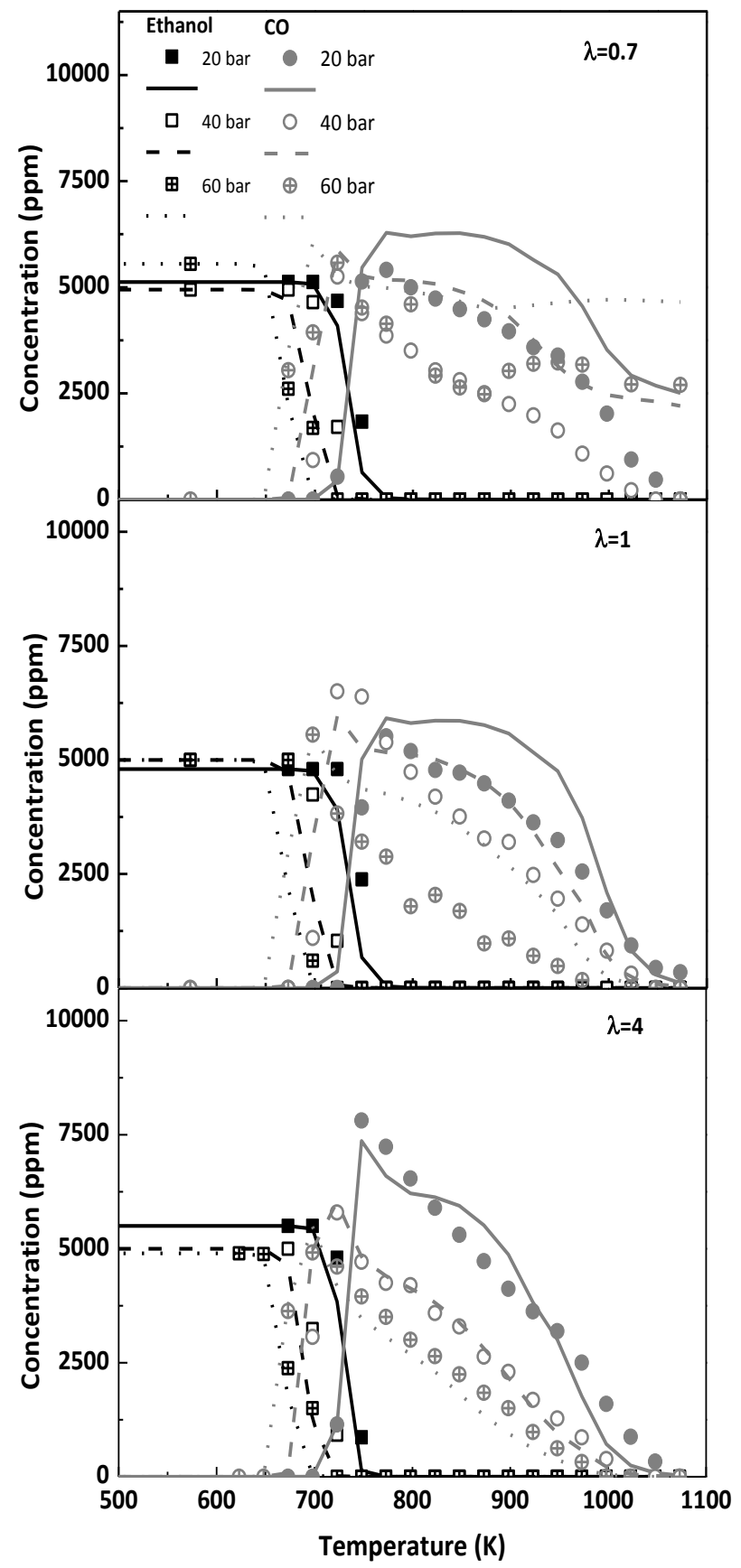

372 Figure. 3. Influence of the pressure change on the concentration profiles of ethanol and $\mathrm{CO}$, as a function of temperature, for the conditions named as sets 1-9 in Table 1. 


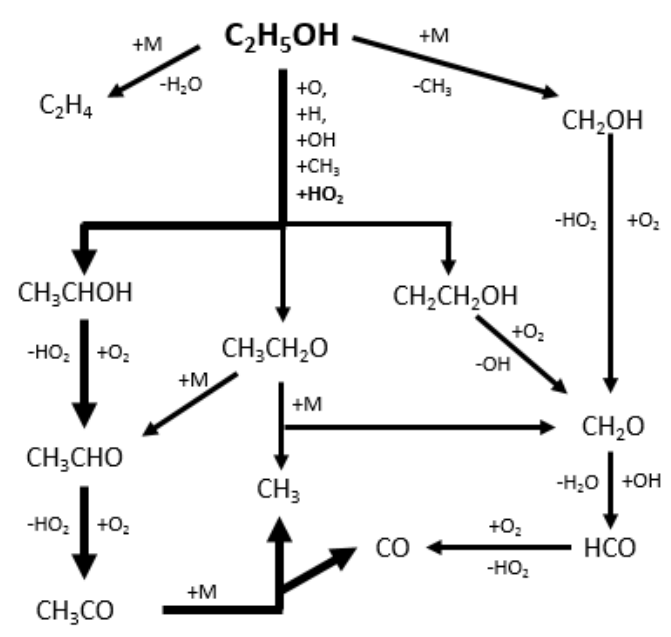

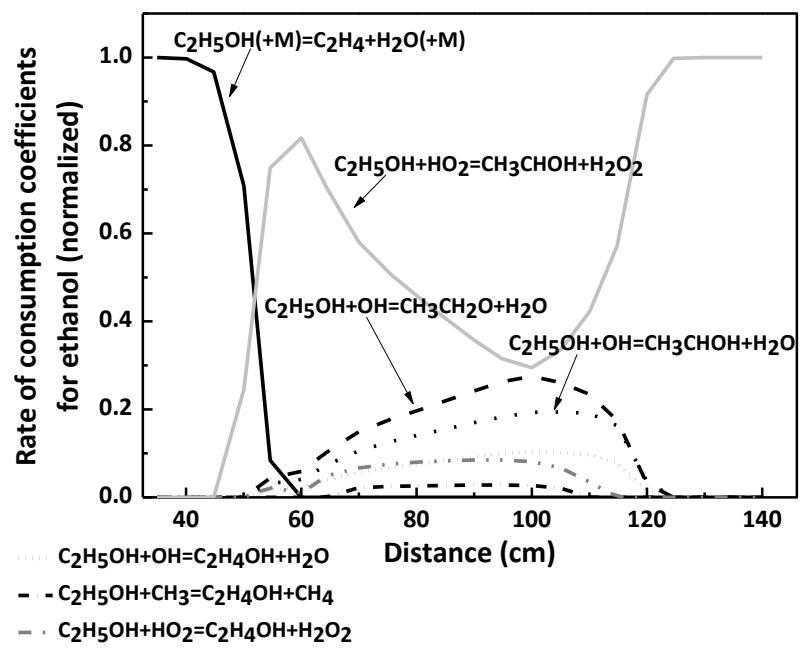

376 Figure 4. Left: reaction path diagram for ethanol consumption and product formation. Right: normalized rate-of-consumption coefficients for ethanol along the reactor (for the conditions of set 4 in Table 1: 20 bar, $\lambda=1$ and $725 \mathrm{~K})$. 


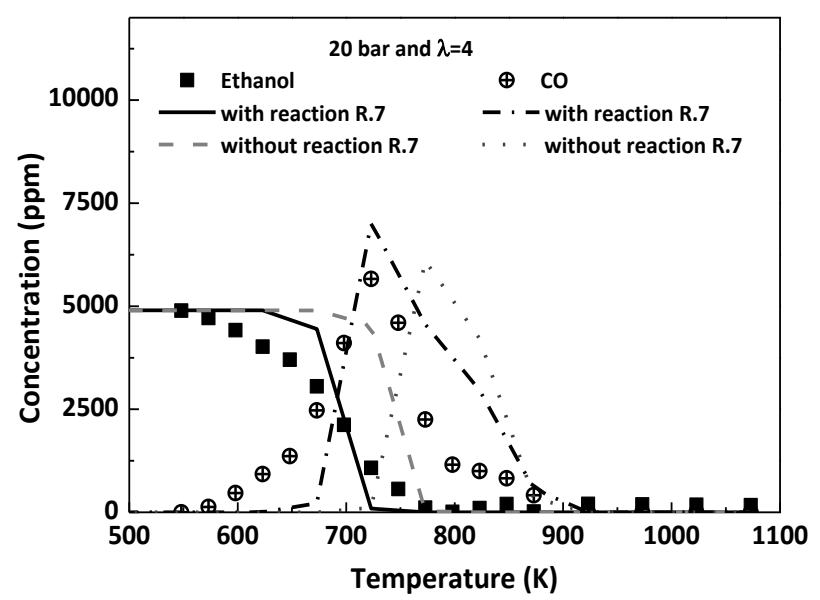

381 Figure 5. Improvement in modeling predictions for ethanol and CO concentration, with and without reaction R.7 in our mechanism, for the conditions named as set 16 in Table 1. 


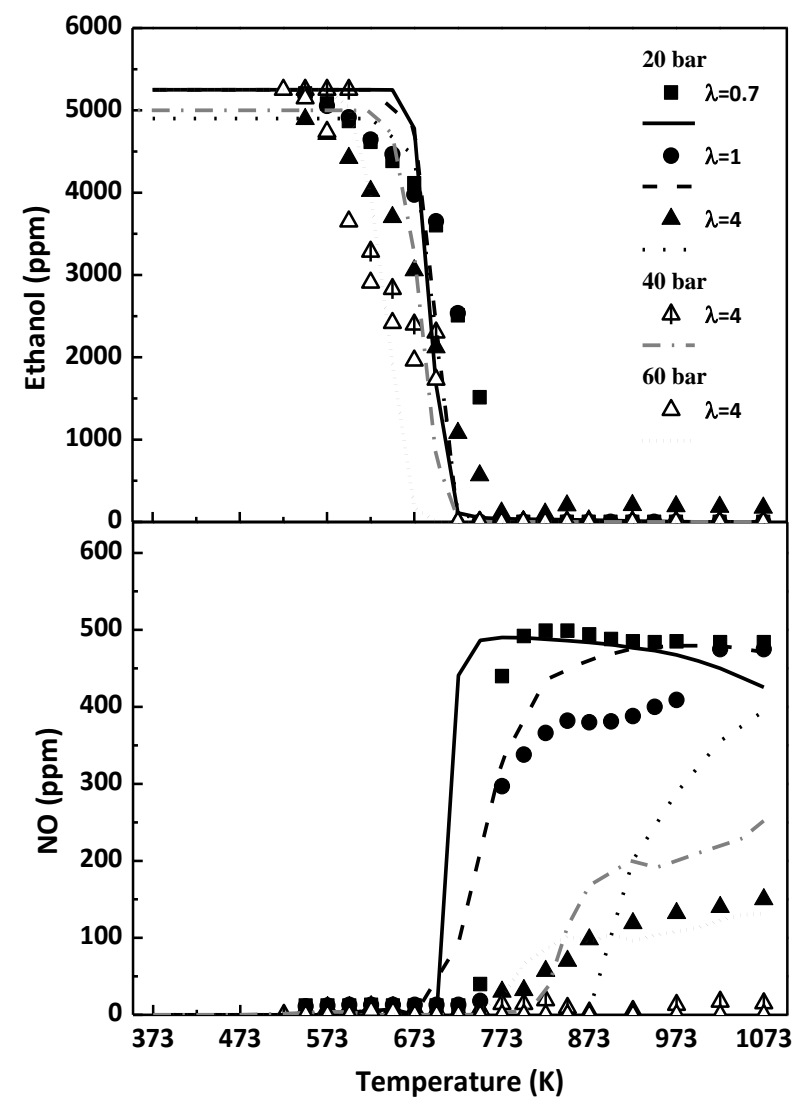

383 Figure 6. Influence of the air excess ratio and pressure on the concentration profiles of ethanol (top) and NO (bottom) for the conditions named as sets 10, 13 and 16-18 in Table 1. 

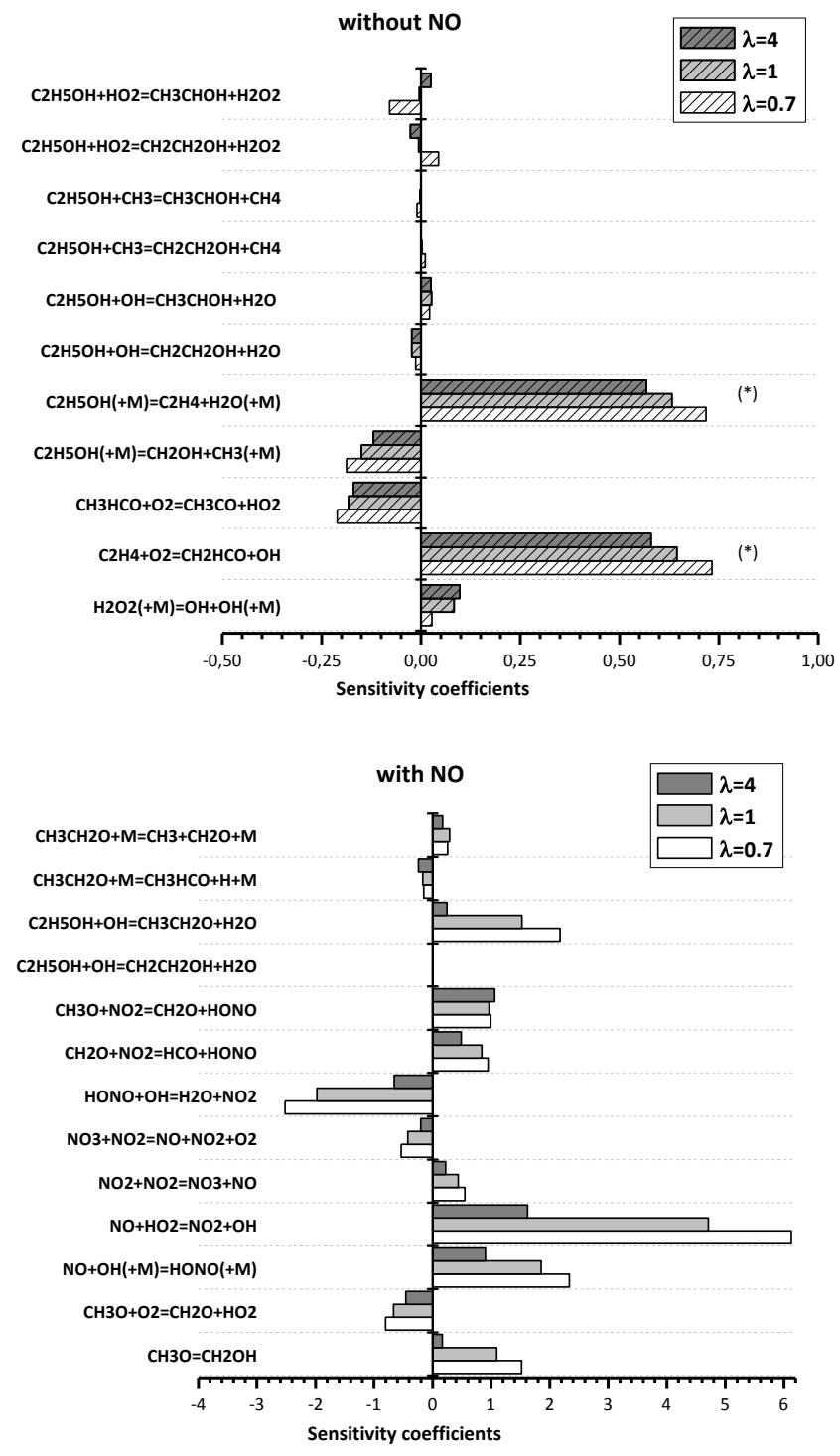

386 Figure 7. Sensitivity analysis for CO for different air excess ratios and 20 bar. Top: in the absence of NO (at $387698 \mathrm{~K})$. Bottom: in the presence of NO (at $648 \mathrm{~K}) .\left({ }^{*}\right)$ The sensitivity coefficients have been divided by two. 
389 List of Supplementary Materials (L. Marrodán et al., High-pressure ethanol oxidation and its interaction with $390 \quad$ NO Fuel 2017)

$391 \quad$ 1/ Kinetic model: mechanism (CHEMKIN file)

$392 \quad 2 /$ Supplementary material (PDF file)

$393 \quad 3 /$ Experimental data (Excel file) 